\title{
Chromosomal radiosensitivity in head and neck cancer patients: evidence for genetic predisposition?
}

\author{
K De Ruyck ${ }^{*, 1}$, V de Gelder', M Van Eijkeren², T Boterberg', W De Neve', A Vral' and H Thierens' \\ 'Department of Human Anatomy, Embryology, Histology and Medical Physics, Ghent University, Proeftuinstraat 86, Ghent B-9000, Belgium; \\ ${ }^{2}$ Department of Radiation Oncology, Ghent University Hospital, De Pintelaan 185, Ghent B-9000, Belgium
}

\begin{abstract}
The association between chromosomal radiosensitivity and genetic predisposition to head and neck cancer was investigated in this study. In all, IOI head and neck cancer patients and 75 healthy control individuals were included in the study. The $\mathrm{G}_{2}$ assay was used to measure chromosomal radiosensitivity. The results demonstrated that head and neck cancer patients had a statistically higher number of radiation-induced chromatid breaks than controls, with mean values of 1.23 and 1.10 breaks per cell, respectively $(P<0.00 \mathrm{I})$. Using the 90 th percentile of the $\mathrm{G}_{2}$ scores of the healthy individuals as a cutoff value for chromosomal radiosensitivity, $26 \%$ of the cancer patients were radiosensitive compared with $9 \%$ of the healthy controls $(P=0.008)$. The mean number of radiation-induced chromatid breaks and the proportion of radiosensitive individuals were highest for oral cavity cancer patients ( 1.26 breaks per cell, 38\%) and pharynx cancer patients (I.27 breaks per cell, 35\%). The difference between patients and controls was most pronounced in the lower age group ( $\leqslant 50$ years, 1.32 breaks per cell, 38\%) and in the non- and light smoking patient group ( $\leqslant 10$ pack-years, 1.28 breaks per cell, 46\%). In conclusion, enhanced chromosomal radiosensitivity is a marker of genetic predisposition to head and neck cancer, and the genetic contribution is highest for oral cavity and pharynx cancer patients and for early onset and non- and light smoking patients.
\end{abstract}

British Journal of Cancer (2008) 98, 1723- 1728. doi: I0.1038/sj.bjc.6604345 www.bjcancer.com

Published online 15 April 2008

(c) 2008 Cancer Research UK

Keywords: head and neck cancer; chromosomal radiosensitivity; genetic predisposition

Enhanced chromosomal radiosensitivity has been observed in a large number of patients with cancer-prone genetic diseases such as ataxia-telangiectasia and Nijmegen breakage syndrome (Gatti, 2001). Several studies have shown that enhanced chromosomal radiosensitivity is also present in a significant proportion of cancer patients (Scott et al, 1994, 1998, 1999; Parshad et al, 1996; Patel et al, 1997; Terzoudi et al, 2000; Baria et al, 2001, 2002; Buchholz and $\mathrm{Wu}, 2001$; Papworth et al, 2001; Riches et al, 2001; Baeyens et al, 2002, 2005; Ban et al, 2004; Howe et al, 2005; Kolusayin Ozar and Orta, 2005; Mozdarani et al, 2005; Distel et al, 2006; Lisowska et al, 2006; Varga et al, 2006). The majority of data have been collected in studies considering breast cancer patients whose lymphocytes were irradiated in the $\mathrm{G}_{2}$ phase of the cell cycle (Scott et al, 1994, 1999; Parshad et al, 1996; Patel et al, 1997; Terzoudi et al, 2000; Baria et al, 2001; Buchholz and Wu, 2001; Riches et al, 2001; Baeyens et al, 2002, 2005; Howe et al, 2005; Djuzenova et al, 2006; Docherty et al, 2007). In a high number of these studies, it was found that approximately $40 \%$ of breast cancer patients show an increased $\mathrm{G}_{2}$ chromosomal radiosensitivity (Scott et al, 1994, 1999; Baria et al, 2001; Buchholz and Wu, 2001; Riches et al, 2001; Baeyens et al, 2002, 2005). As it was also shown that healthy firstdegree relatives of breast cancer patients have an enhanced $\mathrm{G}_{2}$ sensitivity (Parshad et al, 1996; Patel et al, 1997), it has been

*Correspondence: Dr K De Ruyck; E-mail: kim.deruyck@UGent.be Received 7 December 2007; revised 6 March 2008; accepted 10 March 2008; published online 15 April 2008 suggested that this elevated in vitro radiosensitivity may be a marker of low-penetrant cancer-predisposing genes (Roberts et al, 1999).

There is also indirect evidence for the existence of low-penetrant predisposing genetic factors for head and neck cancers (Sturgis et al, 2004). Although tobacco and alcohol consumption play a major role in the aetiology of head and neck squamous cell carcinoma (HNSCC), several large family studies demonstrated a three- to eightfold increased risk of HNSCC in first-degree relatives of patients with HNSCC (Copper et al, 1995; Foulkes et al, 1995, 1996). Furthermore, only a fraction of frequently exposed individuals develop HNSCC and up to $20 \%$ of all HNSCC patients develop the disease without any exposure to the main risk factors (Sturgis et al, 2004). Finally, data emerging from case-control studies using several phenotypic and genotypic assays support the hypothesis of genetic susceptibility for HNSCC (Sturgis and Wei, 2002). Until recently, most of the studies evaluating phenotypic assays as possible marker for head and neck cancer susceptibility focused on the analysis of chromosomal damage in lymphocytes after mutagen exposure (Schantz and Hsu, 1989; Schantz et al, 1989; Bondy et al, 1993; Spitz et al, 1993; Cloos et al, 1996; Wang et al, 1998; Wu et al, 1998; Zhu et al, 2002; Szekely et al, 2005; Xiong et al, 2007). Studies analysing chromosomal damage after in vitro irradiation are, however, limited and often comprise a low number of patients (Terzoudi et al, 2000; Papworth et al, 2001; Ban et al, 2004; Distel et al, 2006; Lisowska et al, 2006). Nevertheless, both Terzoudi et al (2000) and Lisowska et al (2006) reported enhanced chromosomal radiosensitivity in larynx cancer patients, 
and Papworth et al (2001) observed increased chromosomal radiosensitivity in young head and neck cancer patients.

In the present study, we investigated the association between chromosomal radiosensitivity and genetic predisposition to head and neck cancer using the $G_{2}$ assay for peripheral blood lymphocytes. An analysis of the data according to tumour histology and tumour location was performed. In addition, the influence of age of onset of the disease and the effect of smoking habits on genetic predisposition was investigated.

\section{MATERIALS AND METHODS}

\section{Population}

The study population consisted of 101 head and neck cancer patients recruited from the Radiation Oncology Department of the Ghent University Hospital between January 2003 and October 2005. All patients were newly diagnosed, previously untreated and histologically confirmed. The cases included 83 squamous cell carcinomas (SCCs), 12 adenocarcinomas (ACs) and 6 other or unknown carcinomas. A total of 13 patients had cancer of the oral cavity, 37 patients suffered from pharyngeal cancer, 29 patients had laryngeal cancer and 22 patients were diagnosed with sinus

Table I Characteristics of the study population

\begin{tabular}{lcc}
\hline Characteristic & $\begin{array}{c}\text { Controls (\%) } \\
(\mathbf{n}=\mathbf{7 5 )}\end{array}$ & $\begin{array}{c}\text { Patients (\%) } \\
(\mathbf{n}=\mathbf{1 0} \mathbf{I})\end{array}$ \\
\hline Sex & & \\
$\quad$ Male & $41(54.7)$ & $84(83.2)$ \\
$\quad$ Female & $34(45.3)$ & $17(16.8)$ \\
Mean age \pm s.d. & $45 \pm 13.7$ & $60 \pm 10.0$ \\
Anatomic tumour location & & \\
Oral cavity & - & $13(12.9)$ \\
Pharynx & - & $37(36.6)$ \\
Larynx & - & $29(28.7)$ \\
Other and unknown & - & $22(21.8)$ \\
Tumour histology & - & $83(82.2)$ \\
$\quad$ Squamous cell carcinoma (SCC) & - & $12(11.9)$ \\
Adenocarcinoma & $6(5.9)$ \\
Other and unknown & - & $33 \pm 21.5$ \\
Mean pack-years \pm s.d. & $7 \pm 11.6$ & $28 \pm 27.9$ \\
Mean drinks per week \pm s.d. & $6 \pm 5.4$ & \\
\hline
\end{tabular}

cancer or cancer of unknown primary. The population consisted of 84 men and 17 women, and the mean age of the patients at the time of treatment was 60 years (range: 33-91 years) (Table 1).

From each patient in the study, a heparinised blood sample was taken before therapy and the $G_{2}$ assay was performed on the sampling day. At the same time, parallel cultures from healthy individuals were started. The samples of the healthy control individuals were collected at the Occupational Medicine Department of the Ghent University Hospital. Details of the control population are described in Table 1 . The study was approved by the Ethical Committee of the Ghent University Hospital. All study participants signed an informed consent form and completed a detailed questionnaire on smoking and drinking habits. Smoking was quantified by the degree of tobacco consumption categorised as pack-years ( 1 pack-year $=20$ cigarettes per day for 1 year). Alcohol exposure was determined by the number of alcoholic drinks per week. For four patients and two control individuals, no smoking and drinking data were available.

\section{$\mathrm{G}_{2}$ assay}

The $\mathrm{G}_{2}$ assay procedure of the Paterson Institute (Manchester) was applied with some minor changes. Briefly, heparinised blood was kept at room temperature before culturing within $4 \mathrm{~h}$ after prelevation. To a tissue culture flask $\left(25 \mathrm{~cm}^{2}\right), 0.5 \mathrm{ml}$ blood was added to $4.5 \mathrm{ml}$ complete RPMI-1640 culture medium supplemented with $10 \%$ fetal calf serum (Invitrogen, Merelbeke, Belgium), $1 \%$ L-glutamine, $50 \mathrm{U} \mathrm{ml}^{-1}$ penicillin and $50 \mu \mathrm{g} \mathrm{ml}^{-1}$ streptomycin. The lymphocytes were stimulated to divide with $1 \%$ phytohemagglutinin (Invitrogen). Per donor two cultures were started, one served as control, the other for in vitro irradiation. After $70 \mathrm{~h}$ incubation in a $\mathrm{CO}_{2}$ incubator at $37^{\circ} \mathrm{C}$, the cultures were irradiated with a dose of $0.4 \mathrm{~Gy}{ }^{60} \mathrm{Co}$ rays at $37^{\circ} \mathrm{C}$. At $30 \mathrm{~min}$ post irradiation, $75 \mu \mathrm{l}$ colcemid (final concentration $0.15 \mu \mathrm{g} \mathrm{ml}^{-1}$; Sigma-Aldrich, Bornem, Belgium) was added to block the cells at metaphase, and at $90 \mathrm{~min}$ post irradiation the cultures were arrested by putting them on ice for $5 \mathrm{~min}$. The cells were harvested by centrifugation of the samples, and the cell pellets were resuspended in $5 \mathrm{ml}$ of $0.075 \mathrm{M} \mathrm{KCl}$ for $15 \mathrm{~min}$ on ice. After the hypotonic shock, the cells were fixed three times in $5 \mathrm{ml}$ cold methanol/acetic acid $(3: 1)$. Finally, cells were dropped on clean slides and stained with $4 \%$ Azur B SCN solution (Polylab, Merksem, Belgium). Fifty well-spread metaphases were analysed by two independent scorers on coded slides for the appearance of chromatid breaks. All types of single chromatid breaks where a clear discontinuity was present were scored (Bryant et al, 2002).

Table 2 Overview of the $G_{2}$ data

Head and neck cancer patients

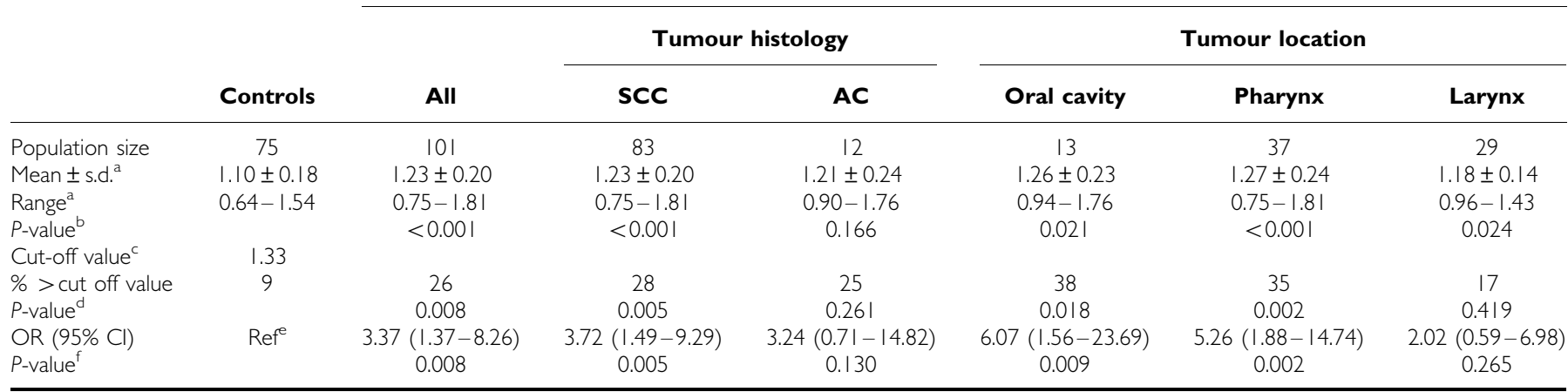

AD, adenocarcinoma; $\mathrm{Cl}$, confidence interval; OR, odds ratio; SCC, squamous cell carcinoma. ${ }^{a}$ Number of chromatid breaks per cell. ${ }^{\mathrm{b}}$ Mann-Whitney test. ${ }^{\mathrm{c}} 90 \mathrm{0th}$ percentile of the control population. ${ }^{d} \chi^{2}$ test. ${ }^{e}$ Ref, reference: control individuals with $\leqslant 1.33$ breaks per cell were used as reference. ${ }^{f}$ Logistic regression. 


\section{Statistical analysis}

Statistical analysis was performed by SPSS 12.0 software (SPSS Inc., Chicago, IL, USA). For the comparison of the mean $\mathrm{G}_{2}$ scores between different groups, the Mann-Whitney test was applied. Differences in the proportions of radiosensitive individuals in the different populations were compared using the $\chi^{2}$ test. Unconditional logistic regression analyses were performed to calculate ORs (odds ratios) and 95\% CIs (95\% confidence intervals). Pearson correlation coefficients were used to study the correlation between aberration frequencies, age, smoking and drinking.

\section{RESULTS}

Chromosomal radiosensitivity $G_{2}$ data were collected for 75 healthy individuals and 101 head and neck cancer patients. For each sample, the spontaneous yield of chromatid breaks was subtracted from the yield in irradiated cells to obtain the radiationinduced aberration yield.

The results for the head and neck cancer patients and for the healthy individuals are summarised in Table 2 and graphically displayed in Figures 1 and 2. The average yield of radiationinduced chromatid breaks per cell was 1.10 for healthy individuals and 1.23 for all head and neck cancer patients $(P<0.001)$. According to tumour histology, patients with SCC and AC were considered. Patients with SCC had 1.23 breaks per cell $(P<0.001)$, whereas those with AC had 1.21 breaks per cell $(P=0.166)$. Using the 90th percentile of the $G_{2}$ scores of the healthy individuals as a cutoff value for chromosomal radiosensitivity (1.33 breaks per cell), $26 \%$ of all cancer patients, $28 \%$ of SCC patients and $25 \%$ of AC patients were radiosensitive compared with $9 \%$ of the healthy individuals $(P=0.008,0.005$ and 0.261 , respectively). This corresponds, respectively, to ORs with respect to cancer incidence of $3.37(P=0.008), 3.72(P=0.005)$ and $3.24(P=0.130)$ for individuals with $\mathrm{G}_{2}$ scores exceeding 1.33 breaks per cell (Table 2). According to anatomic tumour location, three patients subgroups were considered: (1) patients with oral cavity cancer, (2) patients with pharyngeal cancer and (3) patients with laryngeal cancer. Patients from each subgroup had significantly more chromatid breaks per cell compared with the individuals from the healthy control group $(P=0.021,<0.001$ and 0.024 , respectively). On the basis of the 90 th percentile cutoff value, $38 \%$ of the oral cavity cancer patients, $35 \%$ of the pharynx cancer patients and $17 \%$ of the larynx cancer patients were radiosensitive $(P=0.018,0.002$ and 0.419 , respectively). Consequently, individuals with increased chromosomal radiosensitivity had a six-, five- or two-fold increased risk to develop oral cavity cancer, pharynx cancer or larynx cancer $(P=0.009,0.002$ or 0.265$)$, respectively.

For further analyses, the patients were stratified according to age, smoking habits and alcohol intake, and chromosomal radiosensitivity was evaluated in the subsequent subgroups. The results of these analyses are presented in Table 3. No significant effect of age was seen on radiation-induced aberrations in individual patients and controls $(P>0.100)$, but stratified analysis showed the highest mean $G_{2}$ scores for the youngest patients. Patients with ages $\leqslant 50$, between $>50$ and $\leqslant 70$, and $>70$ years had 1.32, 1.22 and 1.18 breaks per cell, respectively. Except for the oldest patient group $(P=0.269)$, these results were significantly different from the control population $(P=0.004$ and $<0.001$, respectively). Using the cutoff value of the healthy control group, $38 \%$ of the patients with age $\leqslant 50$ years $(P=0.009)$ were radiosensitive. Consequently, radiosensitive individuals $\leqslant 50$ years had a six-fold increased risk for developing head and neck cancer $(P=0.007)$. There was also no correlation between smoking and radiation-induced aberrations in patients and controls $(P>0.130)$. Nevertheless, the highest mean $G_{2}$ scores were found for non- and light smoking patients. Patients with $\leqslant 10$, between $>10$ and $\leqslant 25$, and $>25$ pack-years had 1.28, 1.22 and 1.21 breaks per cell,
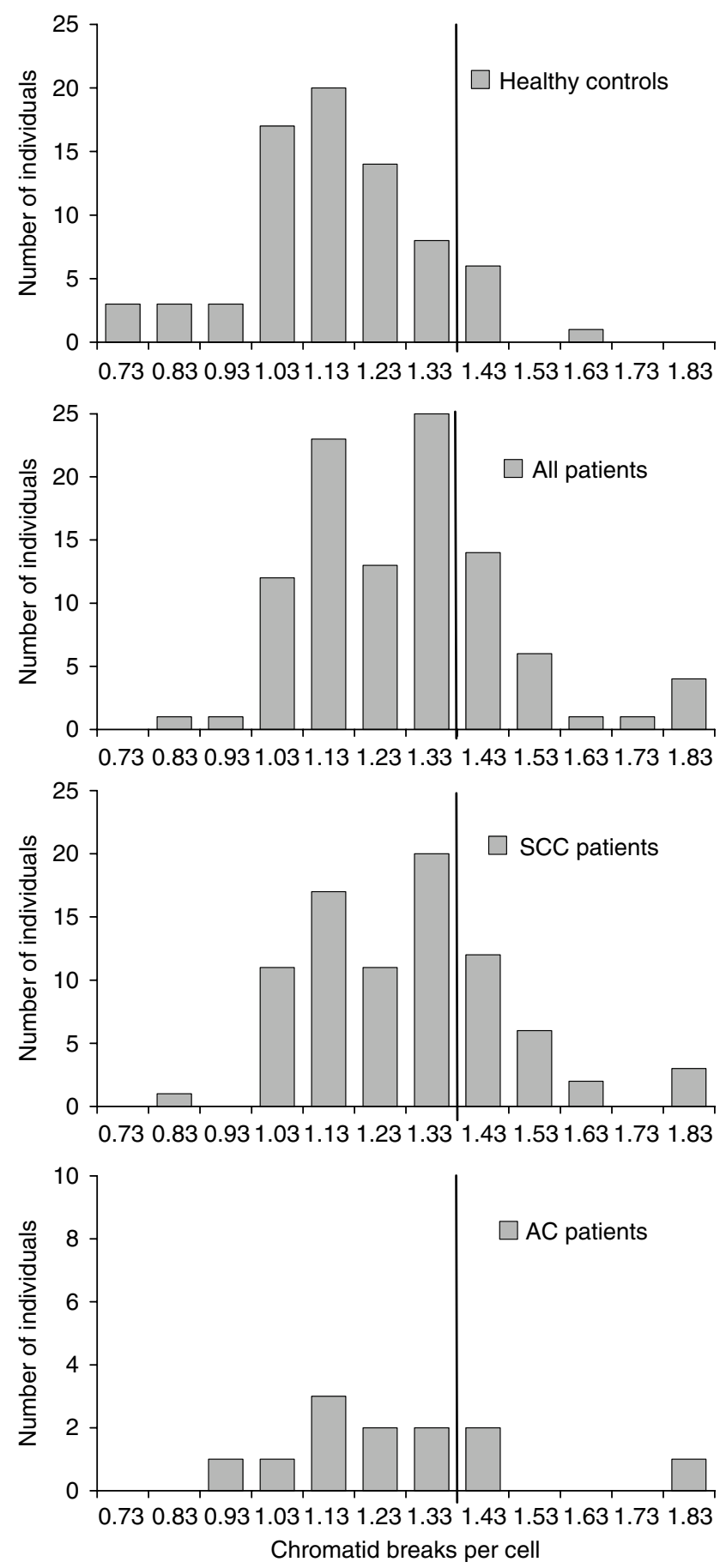

Figure I Distribution of radiation-induced $G_{2}$ chromatid breaks in healthy individuals $(n=75)$, all head and neck cancer $(n=|0|)$, SCC $(n=83)$ and AC patients $(n=12)$. The vertical line represents the 90th percentile cutoff point.

respectively. The results of all subgroups defined according to smoking habits were statistically significant compared with the control population ( $P=0.006,0.007$ and 0.001 , respectively). On the basis of the cutoff value of the healthy control group, $46 \%$ of the patients with $\leqslant 10$ pack-years $(P=0.003)$ were radiosensitive. Accordingly, an OR of $8.33(P=0.002)$ was found for non- and light smoking individuals. A similar trend was not seen for alcohol intake in the patient population, nor for any of the three parameters in the control population. 

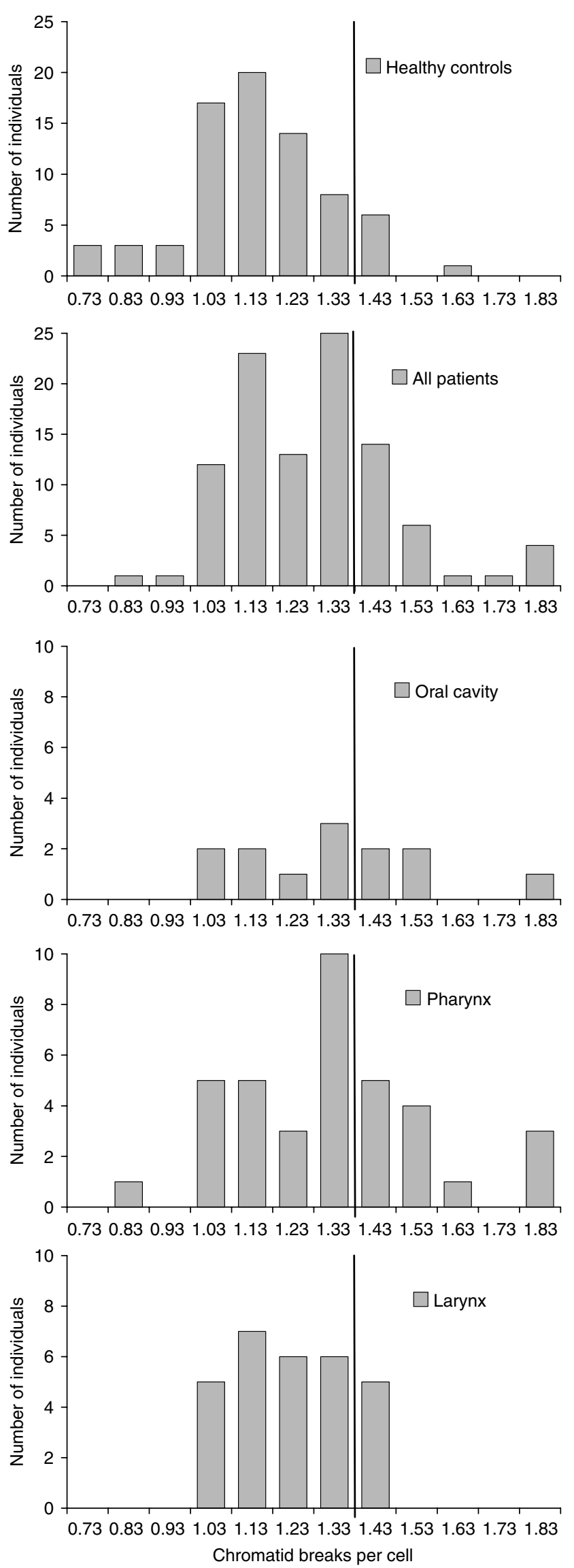

\section{DISCUSSION}

The association between $\mathrm{G}_{2}$ chromosomal radiosensitivity and genetic predisposition to head and neck cancer was investigated in the present study. Moreover, an analysis of the data according to tumour histology and tumour location was performed, and the influence of age of onset of the disease and the effect of smoking habits on genetic predisposition were investigated.

Analysis of the data shows that head and neck cancer patients have a significantly higher mean number of in vitro radiationinduced chromatid breaks per cell than healthy individuals (1.23 vs 1.10 breaks per cell, $P<0.001)$. The observed elevated chromosomal radiosensitivity was independent of tumour histology and tumour location. Patients with SCC and AC, as well as patients with oral cavity, pharynx and larynx cancers, all showed an increased mean number of radiation-induced chromosomal aberrations compared with the control group. Except for the AC patients, all results were statistically significant. With respect to laryngeal cancer, these results are in agreement with the findings of Terzoudi et al (2000) and Lisowska et al (2006), who both reported enhanced chromosomal radiosensitivity in larynx cancer patients. This increase was statistically significant in the latter study, but in the study of Terzoudi et al (2000), the statistical significance was not mentioned. In the study of Lisowska et al, a very different experimental protocol was used compared with the one applied in the present study. Although five times higher irradiation doses were used ( 2 vs $0.4 \mathrm{~Gy}$ in the present study), five times lower mean $\mathrm{G}_{2}$ values were obtained for larynx cancer patients $(0.22$ vs 1.18 breaks per cells in the present study). This discrepancy is at least partly due to the fact that in the study of Lisowska et al, chromatid breaks were analysed in metaphase cells $4.5 \mathrm{~h}$ post irradiation, whereas in the present study chromatid breaks were analysed in metaphase cells $1.5 \mathrm{~h}$ post irradiation. An exponential decline of chromatid breaks with time after irradiation has been demonstrated in the past by our research group and supports the observed differences in absolute chromatid break numbers in both studies (Vral et al, 2002). Concerning various head and neck cancer patients, Papworth et al (2001) reported a nonsignificant increase in mean radiation-induced chromosomal aberrations in these patients. Next to the positive association found between high levels of radiation-induced chromatid breaks and increased risk for head and neck cancer, several studies also reported a positive association between high frequencies of chromatid breaks after bleomycin or benzo[a]pyrene diol epoxide (BPDE) exposure and elevated risk for head and neck cancer (Cloos et al, 1996; Wang et al, 1998; Wu et al, 1998; Zhu et al, 2002; Szekely et al, 2005; Xiong et al, 2007). As radiation as well as bleomycin and BPDE cause DNA damage, both assays are linked to DNA repair capacity. Consequently, the observed enhanced chromosomal radiosensitivity in cancer patients indicates that suboptimal repair of DNA damage contributes to the genetic susceptibility to head and neck cancer. Alternatively, the observed enhanced chromosomal radiosensitivity may also result from a less efficient $G_{2} / M$ checkpoint, as it has been shown that $\mathrm{G}_{2}$ checkpoint abrogation comprises repair of chromosome damage and that defects in the $\mathrm{G}_{2} / \mathrm{M}$ checkpoint are associated with increased cancer risk (Terzoudi et al, 2005; Wu et al, 2005; Zheng et al, 2005).

Although in this study the mean number of radiation-induced aberrations was significantly higher in the studied cancer population compared with the healthy control population, an overlap exists between both groups. Therefore, a cutoff value,

Figure 2 Distribution of radiation-induced $G_{2}$ chromatid breaks in healthy individuals $(n=75)$, all head and neck cancer $(n=|0|)$, oral cavity cancer $(n=13)$, pharynx cancer $(n=37)$ and larynx cancer patients $(n=29)$. The vertical line represents the 90th percentile cutoff point. 
Table 3 Stratification analysis of $G_{2}$ scores in head and neck cancer patients according to age and smoking

\begin{tabular}{|c|c|c|c|c|c|c|c|}
\hline Subgroup & Population size & Mean $G_{2}$ score $^{a}$ & $P$-value ${ }^{b}$ & $\%>$ cutoff value ${ }^{c}$ & $P$-value ${ }^{d}$ & OR $(95 \% \mathrm{Cl})$ & $P$-value ${ }^{e}$ \\
\hline \multicolumn{8}{|l|}{ Age (years) } \\
\hline$\leqslant 50$ & 16 & 1.32 & 0.004 & 38 & 0.009 & $5.83(1.63-20.89)$ & 0.007 \\
\hline$>70$ & 14 & 1.18 & 0.269 & 7 & 0.788 & $0.75(0.09-6.60)$ & 0.793 \\
\hline \multicolumn{8}{|l|}{ Smoking (PY) } \\
\hline$\leqslant 10$ & 13 & 1.28 & 0.006 & 46 & 0.003 & $8.33(2.18-31.78)$ & 0.002 \\
\hline
\end{tabular}

$\mathrm{Cl}$, confidence interval; OR, odds ratio; PY, pack-years. ${ }^{a}$ Number of chromatid breaks per cell. ${ }^{b}$ Mann-Whitney test, compared with the control population. ${ }^{\mathrm{c}} \mathrm{Cutoff}$ value $=90 \mathrm{th}$ percentile of the control population $=1.33$ breaks per cell. ${ }^{~} \chi^{2}$ test, compared with the proportion of control individuals with a $G_{2}$ score $>$ cutoff value. ${ }^{e}$ Logistic regression, control individuals with $\leqslant 1.33$ breaks per cell were used as reference.

above which an individual can be considered as radiosensitive, was determined (Scott et al, 1999). With this value, the proportion of radiosensitive individuals can be compared between different populations. As in most studies, the 90th percentile of the normal population was considered as cutoff point. Using this threshold for chromosomal radiosensitivity, $26 \%$ of the head and neck cancer patients were radiosensitive compared with $9 \%$ of the healthy individuals $(P=0.008)$. A high proportion of radiosensitive cases (31\%) among various head and neck cancer patients have also been reported by Papworth et al (2001). Subdividing our large patient group according to anatomic location of the tumour revealed that the high $\mathrm{G}_{2}$ scores were mainly attributable to the oral cavity and pharyngeal cancer patients of which 38 and $35 \%$, respectively, were radiosensitive $(P=0.018$ and 0.002$)$. Of the laryngeal cancer patients, in contrast, only $17 \%$ of the patients were radiosensitive $(P=0.419)$. In the study of Lisowska et al (2006), a higher and significant proportion of radiosensitive individuals (40\%) among larynx cancer patients was reported. Because a very different experimental protocol is used by Lisowska et al, compared with the present study, this could explain the difference in the number of radiosensitive larynx cancer patients.

In this study, no correlation has been found between radiationinduced aberration frequency and age, pack-years of smoking and drinks per week in patients and controls. Concerning age, this has also been published in other studies (Scott et al, 1999; Riches et al, 2001; Vral et al, 2007). For smoking and drinking exposure, no data are available in the literature for their effect on the level of radiation-induced aberrations. It has, however, been shown that age, smoking and alcohol intake do not influence mutageninduced chromosomal aberrations (Cloos et al, 1996). Despite the lack of correlation on individual level, grouped analysis showed that patients $\leqslant 50$ years and with $\leqslant 10$ pack-years had the highest mean number of chromatid breaks. On the basis of the 90th percentile cutoff value, $38 \%$ of the patients aged 50 years or less were radiosensitive $(P=0.009)$. Similar proportions of in vitro radiosensitive young head and neck cancer patients have also been

\section{REFERENCES}

Baeyens A, Thierens H, Claes K, Poppe B, Messiaen L, De Ridder L, Vral A (2002) Chromosomal radiosensitivity in breast cancer patients with a known or putative genetic predisposition. $\mathrm{Br} J$ Cancer 87: $1379-1385$

Baeyens A, Van Den Broecke R, Makar A, Thierens H, De Ridder L, Vral A (2005) Chromosomal radiosensitivity in breast cancer patients: influence of age of onset of the disease. Oncol Rep 13: 347-353

Ban S, Konomi C, Iwakawa M, Yamada S, Ohno T, Tsuji H, Noda S, Matui Y, Harada Y, Cologne JB, Imai T (2004) Radiosensitivity of peripheral blood lymphocytes obtained from patients with cancers of the reported by Papworth et al (2001) (38\%, $\leqslant 45$ years). Our patient group included only five patients $\leqslant 45$ years but $60 \%$ of them were in vitro radiosensitive $(P=0.008)$. These results indicate that the genetic contribution, as measured by in vitro radiosensitivity, to head and neck cancer risk is higher for early onset cases. This finding for head and neck cancer patients differs from that for breast cancer patients in that no age dependence for $G_{2}$ sensitivity could be found in the latter group (Baeyens et al, 2005). As cancer at young age is a hallmark of heredity, this indicates that individuals at risk for early onset head and neck cancer possess a higher number of low-penetrant predisposing genes or a number of highly penetrant predisposing genes involved in DNA repair pathways compared with late-onset head and neck cancer patients and early onset breast cancer patients. Concerning tobacco exposure, it was found that non- and light smoking patients had the highest mean number of radiation-induced chromatid breaks. This indicates the existence of a larger genetic predisposition in non- and moderately tobacco-exposed individuals and supports the possibility of important gene-environment interactions in the development of head and neck cancer (Xiong et al, 2007).

In conclusion, this study supports the fact that chromosomal radiosensitivity of lymphocytes is a marker of genetic predisposition to head and neck cancer. Analyses of different subgroups revealed that the genetic contribution is highest for oral cavity and pharynx cancer patients and is more pronounced for early onset and non- and light smoking patients.

\section{ACKNOWLEDGEMENTS}

The work was supported by a grant of the Bijzonder Onderzoeksfonds (Ghent University, no. 01109201). We thank all the patients and control donors who participated in this study. We also gratefully acknowledge the contribution of all study nurses of the Ghent University Hospital for the collection of the patient and control samples. breast, head and neck or cervix as determined with a micronucleus assay. J Radiat Res 45: 535-541

Baria K, Warren C, Eden OB, Roberts SA, West CM, Scott D (2002) Chromosomal radiosensitivity in young cancer patients: possible evidence of genetic predisposition. Int J Radiat Biol 78: 341-346

Baria K, Warren C, Roberts SA, West CM, Scott D (2001) Chromosomal radiosensitivity as a marker of predisposition to common cancers? $\mathrm{Br} J$ Cancer 84: 892-896

Bondy ML, Spitz MR, Halabi S, Fueger JJ, Schantz SP, Sample D, Hsu TC (1993) Association between family history of cancer and mutagen 
sensitivity in upper aerodigestive tract cancer patients. Cancer Epidemiol Biomarkers Prev 2: $103-106$

Bryant PE, Gray L, Riches AC, Steel CM, Finnon P, Howe O, Kesterton I, Vral A, Curwen GB, Smart V, Tawn EJ, Whitehouse CA (2002) The $\mathrm{G}_{2}$ chromosomal radiosensitivity assay. Int J Radiat Biol 78: 863-866

Buchholz TA, Wu XF (2001) Radiation-induced chromatid breaks as a predictor of breast cancer risk. Int J Radiat Oncol Biol Phys 49: 533-537

Cloos J, Spitz MR, Schantz SP, Hsu TC, Zhang ZF, Tobi H, Braakhuis BJM, Snow GB (1996) Genetic susceptibility to head and neck squamous cell carcinoma. J Natl Cancer Inst 88: 530 - 535

Copper MP, Jovanovic A, Nauta JJP, Braakhuis BJM, De Vries N, Van der Waal I, Snow GB (1995) Role of genetic factors in the etiology of squamous cell carcinoma of the head and neck. Arch Otolaryngol Head Neck Surg 121: $157-160$

Distel LVR, Neubauer S, Keller U, Sprung CN, Sauer R, Grabenbauer GG (2006) Individual differences in chromosomal aberrations after in vitro irradiation of cells from healthy individuals, cancer and cancer susceptibility syndrome patients. Radiother Oncol 81: 257-263

Djuzenova CS, Muhl B, Fehn M, Oppitz U, Muller B, Flentje M (2006) Radiosensitivity in breast cancer assessed by the Comet and micronucleus assays. Br J Cancer 94: 1194-1203

Docherty Z, Georgiou A, Langman C, Kesterton I, Rose S, Camplejohn R, Ball J, Barwell J, Gilchrist R, Pangon L, Berg J, Hodgson S (2007) Is chromosome radiosensitivity and apoptotic response to irradiation correlated with cancer susceptibility? Int J Radiat Biol 83: 1-12

Foulkes WD, Brunet JS, Kowalski LP, Narod SA, Franco EL (1995) Family history of cancer is a risk factor for squamous cell carcinoma of the head and neck in Brazil: a case - control study. Int J Cancer 63: 769-773

Foulkes WD, Brunet JS, Sieh W, Black MJ, Shenouda G, Narod SA (1996) Familial risks of squamous cell carcinoma of the head and neck: retrospective case-control study. BMJ 313: 716-721

Gatti RA (2001) The inherited basis of human radiosensitivity. Acta Oncol 40: $702-711$

Howe OL, Daly PA, Seymour C, Ormiston W, Nolan C, Mothersill C (2005) Elevated $\mathrm{G}_{2}$ chromosomal radiosensitivity in Irish breast cancer patients: a comparison with other studies. Int J Radiat Biol 81: 373-378

Kolusayin Ozar MO, Orta T (2005) The use of chromosome aberrations in predicting breast cancer risk. J Exp Clin Cancer Res 24: 217-222

Lisowska H, Lankoff A, Wieczorek A, Florek A, Kuszewski T, Gozdz S, Wojcik A (2006) Enhanced chromosomal radiosensitivity in peripheral blood lymphocytes of larynx cancer patients. Int J Radiat Oncol Biol Phys 6: $1245-1252$

Mozdarani H, Mansouri Z, Haeri SA (2005) Cytogenetic radiosensitivity of $\mathrm{G}(0)$-lymphocytes of breast and esophageal cancer patients as determined by micronucleus assay. J Radiat Res 46: 111-116

Papworth R, Slevin N, Roberts SA, Scott D (2001) Sensitivity to radiationinduced chromosome damage may be a marker of genetic predisposition in young head and neck cancer patients. Br J Cancer 84: 776-782

Parshad R, Price FM, Bohr VA, Cowans KH, Zujewski JA, Sanford KK (1996) Deficient DNA repair capacity, a predisposing factor in breast cancer. Br J Cancer 74: 1-5

Patel RK, Trivedi AH, Arora DC, Bhatavdekar JM, Patel DD (1997) DNA repair proficiency in breast cancer patients and their first-degree relatives. Int J Cancer 73: $20-24$

Riches AC, Bryant PE, Steel CM, Gleig A, Robertson AJ, Preece PE Thompson AM (2001) Chromosomal radiosensitivity in $\mathrm{G}_{2}$-phase lymphocytes identifies breast cancer patients with distinctive tumour characteristics. Br J Cancer 85: 1157-1161

Roberts SA, Spreadborough AR, Bulman B, Barber JBP, Evans DGR, Scott D (1999) Heritability of cellular radiosensitivity: a marker of low-penetrance predisposition genes in breast cancer. Am J Human Genet 65: 784-794

Schantz SP, Hsu TC (1989) Mutagen-induced chromosome fragility within peripheral blood lymphocytes of head and neck cancer patients. Head Neck 11: 337-342
Schantz SP, Hsu TC, Ainslie N, Moser RP (1989) Young adults with head and neck cancer express increased susceptibility to mutagen-induced chromosome damage. JAMA 262: 3313-3315

Scott D, Barber JBP, Levine EL, Burrill W, Roberts SA (1998) Radiationinduced micronucleus induction in lymphocytes identifies a high frequency of radiosensitive cases among breast cancer patients: a test for predisposition? Br J Cancer 77: 614-620

Scott D, Barber JBP, Spreadborough AR, Burrill W, Roberts SA (1999) Increased chromosomal radiosensitivity in breast cancer patients: a comparison of two assays. Int J Radiat Biol 75: 1-10

Scott D, Spreadborough A, Levine E, Roberts SA (1994) Genetic predisposition in breast cancer. Lancet 344: 444

Spitz MR, Fueger JJ, Halabi S, Schantz SP, Sample D, Hsu TC (1993) Mutagen sensitivity in upper aerodigestive tract cancer: a case-control analysis. Cancer Epidemiol Biomarkers Prev 2: 329-333

Sturgis EM, Wei Q, Spitz MR (2004) Descriptive epidemiology and risk factors for head and neck cancer. Semin Oncol 31: 726-733

Sturgis EM, Wei QY (2002) Genetic susceptibility - molecular epidemiology of head and neck cancer. Curr Opin Oncol 14: 310-317

Szekely G, Remenar E, Kasler M, Gundy S (2005) Mutagen sensitivity of patients with cancer at different sites of the head and neck. Mutagenesis 20: $381-385$

Terzoudi GI, Jung T, Hain J, Vrouvas J, Margaritis K, Donta-Bakoyianni C, Makropoulos V, Angelakis P, Pantelias GE (2000) Increased $\mathrm{G}_{2}$ chromosomal radiosensitivity in cancer patients: the role of $\mathrm{cdk} 1 /$ cyclin-B activity level in the mechanisms involved. Int J Radiat Biol 76: $607-615$

Terzoudi GI, Manola KN, Pantelias GE, Iliakis G (2005) Checkpoint abrogation in $\mathrm{G}(2)$ compromises repair of chromosomal breaks in ataxia telangiectasia cells. Cancer Res 65: $11292-11296$

Varga D, Hoegel J, Maier C, Jainta S, Hoehne M, Patino-Garcia B, Michel I, Schwarz-Boeger U, Kiechle M, Kreienberg R, Vogel W (2006) On the difference of micronucleus frequencies in peripheral blood lymphocytes between breast cancer patients and controls. Mutagenesis 21: $313-320$

Vral A, Thierens H, Baeyens A, De Ridder L (2002) Induction and disappearance of $\mathrm{G}_{2}$ chromatid breaks in lymphocytes after low doses of low-LET gamma-rays and high-LET fast neutrons. Int J Radiat Biol 78: $249-257$

Vral A, Thierens H, Baeyens A, De Ridder L (2007) Chromosomal aberrations and in vitro radiosensitivity: intra-individual versus interindividual variability. Toxicol Lett 149: $345-352$

Wang LE, Sturgis EM, Eicher SA, Spitz MR, Hong WK, Wei QY (1998) Mutagen sensitivity to benzo(a)pyrene diol epoxide and the risk of squamous cell carcinoma of the head and neck. Clin Cancer Res 4: $1773-1778$

Wu XF, Gu J, Hong WK, Lee JJ, Amos CI, Jiang H, Winn RJ, Fu KKW, Cooper J, Spitz MR (1998) Benzo[a]pyrene diol epoxide and bleomycin sensitivity and susceptibility to cancer of upper aerodigestive tract. J Natl Cancer Inst 90: 1393-1399

Wu XF, Roth JA, Zhao H, Luo S, Zheng YL, Chiang S, Spitz MR (2005) Cell cycle checkpoints, DNA damage/repair, and lung cancer risk. Cancer Res 65: $349-357$

Xiong P, Hu Z, Li C, Wang LE, El-Naggar AK, Sturgis EM, Wei Q (2007) In vitro benzo[a]pyrene diol epoxide-induced DNA damage and chromosomal aberrations in primary lymphocytes, smoking, and risk of squamous cell carcinoma of the head and neck. Int J Cancer 121: $2735-2740$

Zheng YL, Loffredo CA, Alberg AJ, Yu ZP, Jones RT, Perlmutter D, Enewold L, Krasna MJ, Yung R, Shields PG, Harris CC (2005) Less efficient $\mathrm{G}(2)-\mathrm{M}$ checkpoint is associated with an increased risk of lung cancer in African Americans. Cancer Res 65: 9566-9573

Zhu Y, Spitz MR, Zheng YL, Hong WK, Wu XF (2002) BPDE-induced lymphocytic 3 p21.3 aberrations may predict head and neck carcinoma risk. Cancer 95: 563-568 